\title{
Performance of a High-Resolution X-Ray Microprobe at the Advanced Photon Source*
}

\author{
Z. Cai, B. Lai, W. Yun\%, I. McNulty, A. Khounsary, J. Maser, P. Ilinski, D. \\ Legnini, E. Trakhtenberg, S. Xu, B. Tieman, \\ G. Wiemerslage, and E. Gluskin \\ Experimental Facilities Division, Argonne National Laboratory, Argonne, IL 60439 \\ \%Advanced Light Source, LawrenceBerkeley National Laboratory, Berkeley, CA 94720

\begin{abstract}
We have developed a $\mathrm{x}$-ray microprobe in the energy region from 6 to $20 \mathrm{keV}$ using undulator radiation and zone-plate optics for microfocusing-based techniques and applications at a beamline at the Advanced Photon Source (APS). The performance of the beamline was shown to meet our design objectives, including preservation of the source brilliance and coherence, selectable transverse coherence length and energy bandwidth, high angular stability, and harmonic suppression of the beam. These objectives were achieved by careful thermal management and use of a novel mirror and crystal monochromator cooling geometry. All beamline optical components are water cooled, and the $\mathrm{x}$-ray beam in the experiment station is stable in beam intensity, energy, and position over many days with no active feedback. Using a double-crystal Si(111) monochromator, we have obtained a focal spot size (FWHM) of $0.15 \mu \mathrm{m}(\mathrm{v}) \times 1.0 \mu \mathrm{m}(\mathrm{h})$, and a photon flux of $4 \times 10^{9}$ photons/sec at the focal spot, and thus a photon flux density gain of 15,000 . A circular beam spot of $0.15 \mu \mathrm{m}$ in diameter can be achieved by reducing the horizontal source size using a white beam slit located 43.5 meters upstream of the zone plate, with an order of magnitude less flux in the focal spot.
\end{abstract}

The recent availability of high-brilliance synchrotron radiation sources and $\mathrm{x}$-ray Fresnel zone plate microfocusing optics with high spatial resolution and high focusing efficiency ${ }^{1}$ has made possible the creation of a new tool for material characterization on micron and submicron length scales. A hard x-ray scanning microprobe (HXRSM) that combines microfocusing capabilities with $\mathrm{x}$-ray sensitivity to trace element distributions, crystallographic strain, and the ability to penetrate deep in a specimen, has been developed for high-resolution fluorescence mapping and microdiffraction at the Advanced Photon Source (APS) at Argonne National Laboratory.

The HXRSM utilizes the radiation from the high-brilliance source generated from an electron beam of $7 \mathrm{GeV}$ in the APS storage ring and a 3.3-cm-period undulator (APS undulator A). The energy of the radiation can be tuned from 3.2 to $45 \mathrm{keV}$ by a combination of varying the undulator gap and selecting among the first, third, and fifth harmonics of the undulator. The undulator has been optimized so that continuity in brilliance is achieved when tuning from one harmonic energy to the next.

The HXRSM is installed in a dedicated beamline (2-ID-D) specifically designed and developed for $\mathrm{x}$-ray microscopic applications. Figure 1 schematically illustrates the 2-ID-D beamline. The beamline was specially designed to achieve conservation of 


\section{DISCLAIMIER}

This report was prepared as an account of work sponsored by an agency of the United States Government. Neither the United States Government nor any agency thereof, nor any of their employees, make any warranty, express or implied, or assumes any legal liability or responsibility for the accuracy, completeness, or usefuiness of any information, apparatus, product, or process disclosed, or represents that its use would not infringe privately owned rights. Reference herein to any specific commercial product, process, or service by trade name, trademark, manufacturer, or otherwise does not necessarily constitute or imply its endorsement, recommendation, or favoring by the United States Government or any agency thereof. The views and opinions of authors expressed herein do not necessarily state or reflect those of the United States Government or any agency thereof. 


\section{DISCLAIMER}

Portions of this document may be illegible in electronic image products. Images are produced from the best available original document. 
the source brilliance, selectivity of energy bandwidth, and the capability of reducing the effective source size. The beamline uses a windowless operation between the front end and the beamline to avoid degradation of wavefront due to vacuum barriers. The nominal emittance of the beam in the APS storage ring is $8.2 \times 10^{-9} \mathrm{~m}$-rad. Given a one-percent coupling between the vertical and horizontal emittance and beta functions of $14 \mathrm{~m}$ (horizontal) and $6 \mathrm{~m}$ (vertical), the FWHM source size of the photon beam at the center of the straight section is $52 \mu \mathrm{m}$ (vertical) and $790 \mu \mathrm{m}$ (horizontal). In order to preserve the brilliance, we use a water-cooled grazing-incidence $\left(0.15^{\circ}\right)$ horizontally deflecting mirror (1.2 meters long) as a first optical component. The grazing incidence of the mirror considerably reduces the power density on the reflecting surface and thus improves the performance of the first component. The cutoff of the reflected energy provided by the mirror considerably reduces both total radiation power and heat flux incident on downstream optical components, thus enhancing their performance. The horizontal deflection geometry takes advantage of less stringent requirements in slope error for avoiding brilliance degradation in the horizontal direction because the emittance in that direction is two orders of magnitude larger than that in the vertical direction. Three reflecting surfaces $(\mathrm{Si}, \mathrm{Rh}$, and $\mathrm{Pt})$ cover $\mathrm{x}$-ray energies up to $40 \mathrm{keV}$. Use of the mirror also provides suppression of high-order harmonics of the undulator radiation, which is particularly important for high-energy storage rings like the APS. Either a double-crystal monochromator (DCM) or a double-multilayer monochromator (which will be installed soon) located 64 to 65 meters from the source is used to monochromatize the mirror-reflected undulator beam. The combination of the large monochromator-to-source distance and the power filtering of the mirror reduces the maximum power density at normal incidence at the monochromator to less than $13.3 \mathrm{~W} / \mathrm{mm}^{2}$, thirteen times less than that of a beamline without mirror filtering and with the monochromator located in the first optical enclosure. When a proper mirror coating is used, the maximum heat flux on the first crystal is less than $2.3 \mathrm{~W} / \mathrm{mm}^{2}$. A monolithic, U-shaped, and water-cooled $\mathrm{Si}(111)$ crystal, with less than 2 microradians of tangential slope error over the footprint of the FWHM of the undulator radiation, is used as the first crystal for the DCM. It can handle a peak heat flux of $5 \mathrm{~W} / \mathrm{mm}^{2}$ before the beam brilliance degradation becomes severe.

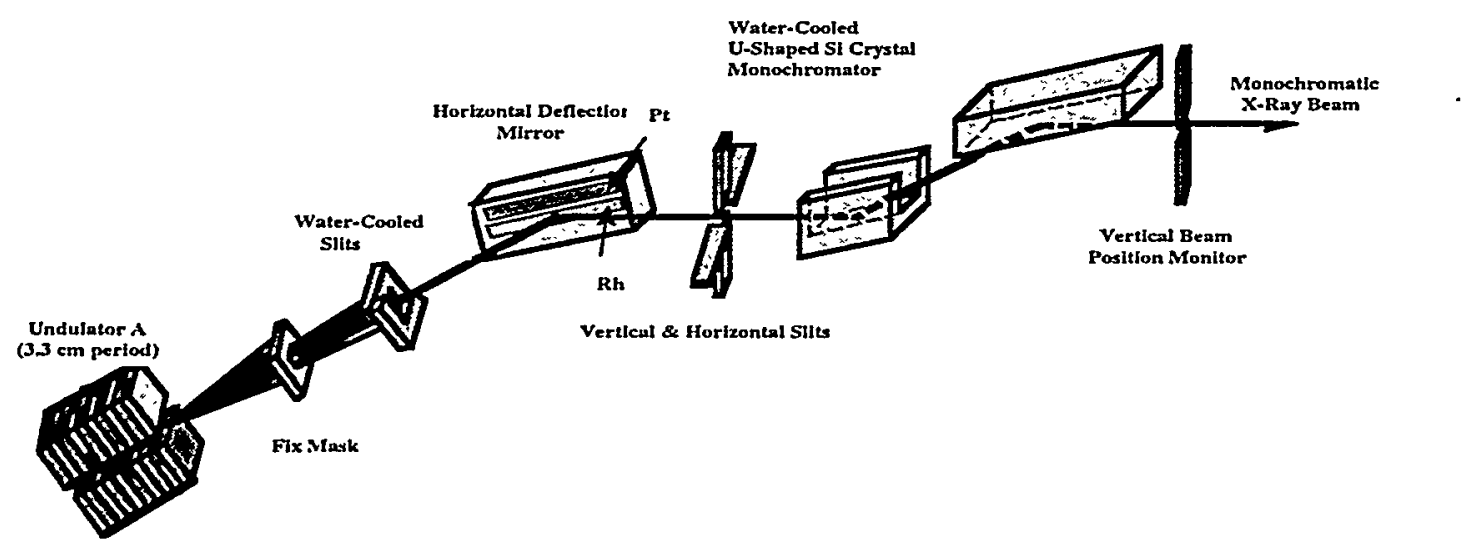

Fig. 1. Schematic illustration of the 2-ID beamline for the HXRSM 
Figure 2 illustrates the HXRSM in the experiment station. The phase zone plates we have developed for the HXRSM have first-order focusing efficiency from $15 \%$ to $40 \%$ within the $\mathrm{x}$-ray energy region from $6 \mathrm{keV}$ to $20 \mathrm{keV}$. $^{2}$ The thickness of the gold zone plates ranges from $1.5 \mu \mathrm{m}$ to $3.5 \mu \mathrm{m}$, and the focal length ranges from $5 \mathrm{~cm}$ to several meters at $8 \mathrm{keV}$. The outermost zone width, which determines the spatial resolution of the focusing optics, has reached $100 \mathrm{~nm}$. Future development of the phase zone plates will improve the spatial resolution and extend the capability of the HXRSM toward higher energy. In the meantime, $x$-ray energies higher than $20 \mathrm{keV}$ can be achieved by employing a multiple-zone-plate stacking technique. The HXRSM is located in the experiment station 71.5 meters away from the source. For a zone plate with a focal length of $10 \mathrm{~cm}$ at $8 \mathrm{keV}$ and a diameter of $150 \mu \mathrm{m}$, we have a demagnification factor of 710. In order to coherently illuminate the zone plate in the horizontal direction so that a horizontal spot size limited by the outermost zone width of the zone plate is obtained, a water-cooled and adjustable slit located 28.3 meters from the center of the insertion device straight section is used to reduce the effective horizontal source size.

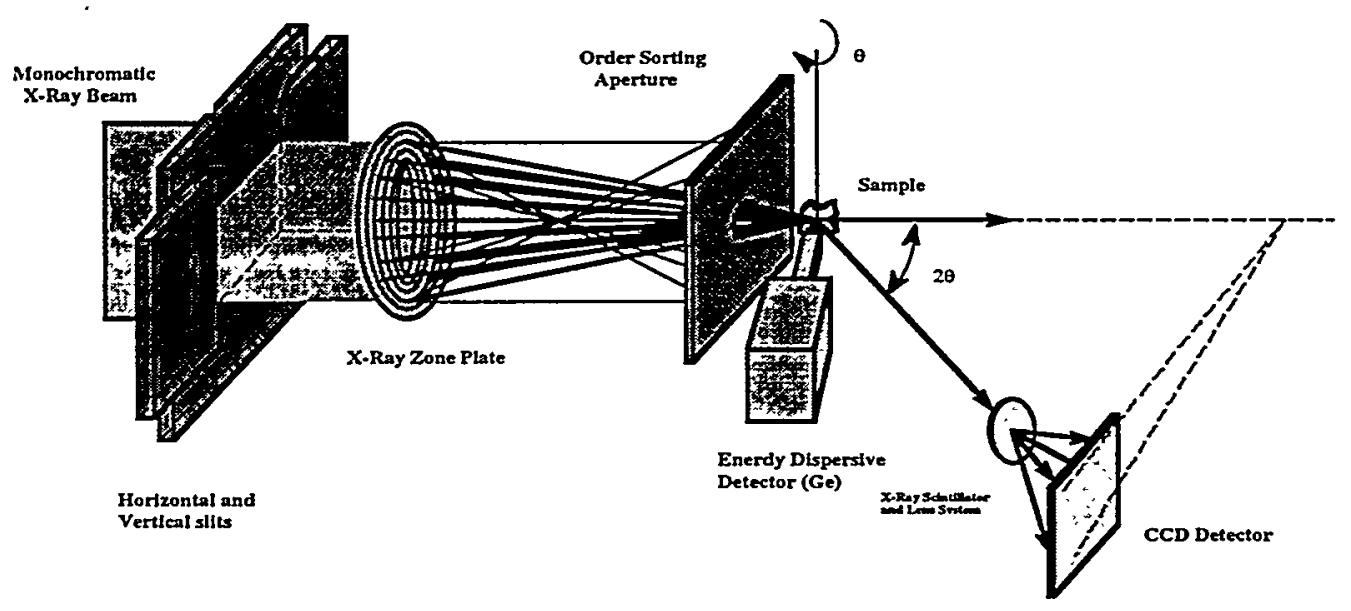

Fig. 2. Zone-plate-based $\mathrm{x}$-ray microprobe in experiment station.

The vertical size of the focal spot generated from a zone plate of $10-\mathrm{cm}$ focal length at $8 \mathrm{keV}$ was measured using a knife-edge scan. The fluorescence intensity was measured while scanning a $100-\AA$-thick $\mathrm{Cr}$ knife edge across the focal spot. The FWHM spot size was obtained by first fitting the fluorescence intensity profile with error functions and then taking derivative of the fitted profile. Using a $\mathrm{Si}(111)$ monochromator, we have obtained a focal spot size (FWHM) of $0.15 \mu \mathrm{m}(\mathrm{v}) \times 1.0$ $\mu \mathrm{m}(\mathrm{h})^{3}$ and a photon flux of $4 \times 10^{9}$ photons/sec at the focal spot and thus a photon flux density gain of 15,000 . A circular beam spot $0.15 \mu \mathrm{m}$ in diameter can be achieved by creating a virtual source (horizontal only) at 43.5 meters upstream of the zone plate, with an order of magnitude less flux in the focal spot.

The HXRSM consists of a zone plate, a platinum order-sorting aperture $(5-30 \mu \mathrm{m})$ for selecting the first-order focused beam, and a sample holder assembly that allows three orthogonal translations and a full rotation around a vertical axis (theta rotation). 
The translation stages on the sample assembly provide a minimum step size of 0.1 $\mu \mathrm{m}$. A peizo-driven $\mathrm{XY}$ stage on the assembly provides finer scanning steps. The sample assembly also contains chi and phi segments for angular positioning of samples when performing diffraction experiments. The HXRSM is equipped with a Ge energy-dispersive detector (a 13-element detector will be installed soon) for fluorescence measurements and a CCD or NaI detector mounted on the 2-theta arm for diffraction measurement.

Since the commissioning of the HXRSM in December 1997, the microprobe has been used for the development of many $\mathrm{x}$-ray microfocusing-based techniques and a broad range of scientific applications. They include high-spatial-resolution fluorescence microscopy, ${ }^{4-6}$ diffraction microscopy, ${ }^{7-10}$ microspectroscopy, ${ }^{7}$ fluorescence correlation spectroscopy ${ }_{11}^{11}$ and fluorescence tomography. ${ }^{12}$ In addition, we are currently carrying out experiments of transmission microscopy and transmission microtomography.

*This work was supported by the Department of Energy, Basic Energy Sciences, Office of Science, under Contract No. W-31-109-ENG-38.

\section{REFERENCES}

1. B. Lai, W. Yun, D. Legnini, Y. Xiao, J. Chrzas, P. Viccaro, V. White, S. Bajikar, D. Denton, F. Cerrina, E. Di Fabrizio, M. Gentili, L. Grella, and M. Baciocchi, Appl. Phys. Lett. 61, 1877(1992).

2. W. Yun, B. Lai, A. Krasnoperova, E. Di Fabrizio, Z. Cai, F. Cerrina, Z. Chen, M. Gentili, E. Gluskin, Rev. Sci. Instrum. 70, 3537 (1999).

3. W. Yun, B. Lai, Z. Cai, J. Maser, D. Legnini, E. Gluskin, Z. Chen, A. Krasnoperova, Y. Valdimirsky, F. Cerrina, E. Di Fabrizio, M. Gentili, Rev. Sci. Instrum. 70, 2238 (1999).

4. P. Ilinski, et al., Argonne Nationál Laboratory, to be submitted, 1999.

5. W. Yun, S. Pratt, R. Miller, Z. Cai, D. Hunter, A. Jarstfer, K. Kemner, B. Lai, H-R. Lee, D. Legnini, W. Rodrigues, C. Smith, J. Synchrotron Rad. 5, 1390 (1998).

6. K. Kemner, W. Yun, Z. Cai, B. Lai, H-R. Lee, J. Maser, D. Legnini, W. Rodrigues, J. Jastrow, R. Miller, S. Pratt, M. Schneegurt, C. Kulpa Jr., J. Synchrotron Rad. 6, 639 (1999).

7. Z. Cai, W. Rodrigues, P. Ilinski, D. Legnini, B. Lai, W. Yun, E. Isaacs, K. Lutterodt, J. Grenko, R. Glew, S. Sputz, R. People, M. Alam, M. Hybertsen, L. Ketelsen, Appl. Phys. Lett. 75, 100 (1999).

8. H. Solak, Y. Vladimirsky, F. Cerrina, B. Lai, W. Yun, Z. Cai, P. Ilinski, D. Legnini, W. Rodrigues, J. Appl. Phys. 86, 884 (1999).

9. H.-R. Lee, D. Kupperman, W. Yun, Z. Cai, W. Rodrigues, Rev. Sci. Instrum. 70, 175 (1999).

10. G. Wong, Y. Li, I. Koltover, C.R. Safinya, Z. Cai, W. Yun, App. Phys. Lett. 73, 2042 (1998).

11. J. Wang, A.K. Sood, Y. Feng, X. Wu, Z. Cai, W. Yun, S.K. Sinha, Phys. Rev. Lett. 80, 1110 (1998).

12. M. Naghedolfeizi, J. -S. Chung, G. E. Ice, W. Yun, Z. Cai, B. Lai, Mat. Res. Soc. Symp. Proc. 524, 233(1998). 